\title{
Genetic transformation of Paulownia elongata S. Y. Hu., mediated by Agrobacterium tumefaciens and biolistic system
}

\author{
Castillo-Martínez, Carlos R. ${ }^{1}$; Gutiérrez-Espinosa, Ma. Alejandra ${ }^{2}$; Cadena-Iñiguez, Jorge ${ }^{3}$; \\ Buenrostro-Nava, Marco T.4; Martínez-Sías, Valeria ${ }^{3}$ \\ ${ }^{1}$ Instituto Nacional de Investigaciones Forestales Agrícolas y Pecuarias Coyoacán, Ciudad de \\ México. ${ }^{2}$ Colegio de Postgraduados, Texcoco, Estado de México. ${ }^{3}$ Campus San Luis Potosí, \\ Salinas de Hidalgo, San Luis Potosí, México. ${ }^{4}$ Universidad Autónoma de Colima, Colima, México. \\ *Corresponding Author: jocadena@colpos.mx
}

\begin{abstract}
Objective: The most appropriate conditions for genetic transformation through direct (bioballistic) and indirect (Agrobacterium tumefaciens) transformation systems in Paulownia elongata were established.

Design/methodology/approach: Starting from in vitro propagation through both direct and indirect organogenesis, internodal stem segments with 0.5 to $1 \mathrm{~cm}$ length were determined as the best explant. The optimum dose for selection media was determined to be $15 \mathrm{mg} \mathrm{L}^{-1}$ of kanamycin. It was possible to obtain transgenic plants under both transformation systems. In the case of Agrobacterium tumefaciens, two hours of incubation, $48 \mathrm{~h}$ of co-cultivation, and optical density of 0.9 were used; while for bioballistics, the best conditions were 120 PSI of shot pressure, shot height at level 6 (16 cm), and vacuum pressure of $22 \mathrm{Hg} \mathrm{mm}$, with particle inflow gun system (PIG).

Results: Both systems produced complete transformants, chimeras, as well as those confirmed by histochemical X-GLUC and PCR analysis, producing a total of 14 positive plants by A. tumefaciens transformation from 26 trials and ten positive plants by the bioballistic system from 30 trials; a construction with chitinase and glucanase, NPT II selection gene and the GUS reporter gene were used.
\end{abstract}

Findings/conclusions: So far, this has been the first report including integration of chitinase and glucanase genes.

Keywords: (BA) 6-bencil-adenine, (ANA) naphthalenic acid, micro-propagation.

\section{INTRODUCTION}

Paulownia elongate U.S.A. in the 20th century, and to Mexico at the end of the 20th century, considered as a species potential for production. It is a forest species of rapid growth and considered an alternative for the establishment of timber-yielding commercial plantations (Tang et al., 1980). Paulownia wood is of low density, which provides lightness and allows its use in manufacture of furniture, crafts, musical instruments, and interior decoration. Because of their quick growth all the species of genus Paulownia have great potential for reforestation and improvement of poor soils (Zhu et al., 1986, Melhuish et al., 1990), they are drought-tolerant and 
adapt to different types of soil, which increases their economic potential (Tang et al., 1980). These qualities, however, make them especially vulnerable for the distribution in plantations under agro-climatic conditions other than those of their original habitat, which may lead to failure, furthermore, susceptibility to soil pathogens such as Rhizoctonia has been reported in different Paulownia species (Mehrotra, 1994; 1997).

The aforementioned, may be moderated by the improvement of their adaptation qualities through genetic transformation. Genetic transformation is a technique that consists in the integration of strange genes to the genome of an individual through the techniques of recombinant DNA, the incorporated genes can improve plant characteristics by direct methods such as bioballistics, which is the acceleration of particles with DNA of desirable features (Vain et al., 1993), or indirectly by Agrobacterium tumefaciens through the Ti plasmid (Herrera-Estrella et al., 1983), thanks to advances in in vitro propagation by different organogenic pathways in species of the Paulownia genus, such as propagation by shoot tips (Song et al., 1990; Sharma et al., 2003), or direct organogenesis from different explants (Song et al., 1991; Castillo et al., 2012); such as by direct embryogenesis (Ipecki and Gozukirmizi, 2003) or indirect embryogenesis (Ipecki and Gozukirmizi, 2004), laying the foundation for the initial processes to carry out research aimed at genetic engineering.

With the purpose of improving the characteristics in Paulownia elongata and the adequate conditions for genetic transformation of this species, studies have been carried out designed to determine the susceptibility of $P$. elongata to Agrobacterium tumefaciens and Agrobacterium rhizogenes, which demonstrated that inoculating shoots generated under in vitro conditions with the strains 542, A281, and C58 of A. tumefaciens, the formation of crown gall is possible with a frequency by $83 \%$. Other plants have promoted quick calli proliferation and root formation in damaged shoot parts, when inoculated with strain R1601 of A. rhizogenes. The molecular analyses showed the presence of opinae, the same as Southern blot tests, which confirmed the existence of the transformation plasmid (T-DNA) in callus as well as in roots (Bergmann et al., 1999). In other species like $P$. fortunei, callus was obtained, transformed after co-cultivating petiole segments with A. tumefaciens strain LBA 4404 with a binary vector (pB121), that included the GUS reporter genes and those of NPT II selection, resistant to kanamycin, and the transformation was confirmed by histochemical tests of the GUS gene expression and the detection of incorporation of the selection gene to the genome of transformed calli (Mohri et al., 2003). Transformation studies, already approached to gene integration with the purpose of conferring some characteristics have been carried out in a hybrid of $P$. tomentosa $\times P$. fortunei, which was transformed via $A$. tumefaciens with vector p43 8PRSI, containing the shiva-1 gene, which codes a bactericide peptide controlled by the promoter gene called CaMV35S. The molecular analyses like PCR, Southern blot, showed the successful integration of the shiva-1 gene in the plant genome, confirming the gene transcription through RT-PCR (Tao et al., 2005).

On the other hand, with the objective to generate resistance to root diseases, studies have been conducted with chitinase genes $(\mathrm{RCH} 10)$ and $\beta$-1-3-glucanase (AGLU) genes, having generated genotypes with tolerance to pathogens like Rhizoctonia solani in Oryza sativa L. (Mao et al., 2003; Li et al., 2004). The aforementioned allows considering the viability of application of these techniques and incorporating them to forest species para generar arboles resistententes a enfermedades como reportaron en Populus deltoides (Zou et al., 2006); therefore the objective of this study was integrating chitinase-glucanase genes through genetic transformation by Agrobacterium-mediated and bioballistic systems in Paulownia elongata (S.Y.Hu.)

\section{MATERIALS AND METHODS \\ Genetic Transformation}

The tests of Agrobacterium tumefaciens-mediated transformation were established based on the principles created by Horsch et al. (1985), utilizing Agrobacterium tumefaciens strain LBA4404, which contains the plasmid pCAMBIA 2301-CHIT-GLU with chitinase and glucanase genes, the GUS reporter gen, and the NPTII selection gen (resistance to kanamycin) with a total size of 11621 base pairs. In order to conduct the transformation assays, internodal segments of $0.5 \mathrm{~m}$ length were used generated in MS medium (Murashigue and Skoog, 1962), cultivated for 35 days to favor the greatest possible internode elongation. Within the culture recipient, shoots of 8 $\mathrm{cm}$ length on average were produced, and the dissected segments were placed in liquid MS medium before their inoculation with the Agrobacterium 
tumefaciens strain. Different transformation conditions were created through variations in bacteria incubation times, bacterium concentration, measurement through culture optical density, and times of co-incubation.

\section{Transformation by Particle Acceleration}

The particle acceleration system utilized was a PIG (Particle Inflow Gun), (Vain et al. 1993) which operates with helium gas and tungsten particles as projectile agents and carrying plasmids at low pressure (40-120 psi) utilizing a vacuum pump (25-30 psi $\mathrm{Hg}$ ). Calli were used for transformation by particle acceleration, which were obtained from internodes cultured in MS medium supplemented with $4 \mathrm{mg} \mathrm{L}^{-1}$ of TDZ, $3 \%$ of sucrose, $0.7 \%$ agar, and $\mathrm{pH}$ of 5.8 . Its growth period took until reaching 1 $\mathrm{cm}^{2}$ at two weeks of $26^{\circ} \mathrm{C}$ under conditions of darkness. Different transformation conditions were established, such as: variations in utilized pressure, regulating helium gas outlet and shot speed, keeping constant plasmid concentration in particles, and shot distance.

\section{Selection of Transformed Segments and Shoot Evaluation}

The segments of the transformation assays were transferred to a selection medium made up of MS medium, added with $4 \mathrm{mg} \mathrm{L}^{-1}$ of $\mathrm{BA}, 0.2 \mathrm{mg} \mathrm{L}^{-1}$ of ANA, $15 \mathrm{mg}$ $\mathrm{L}^{-1}$ of kanamycin, $3 \%$ sucrose, $0.7 \%$ agar, and $\mathrm{pH}$ of 5.8 , the stem segments as well as calli remained for a period of 35 days, time when shoot formation was initiated. The shoots longer than $1.5 \mathrm{~cm}$ were dissected, taking a $2 \mathrm{~mm}$ segment in order to conduct the histochemical XGLUC test and observe the expression of the GUS gene in the tissues, the rest of the shoot was used for DNA extraction required for PCR analysis confirming the integration of the genes of interest for the genome of the transformed shoots.

\section{RESULTS AND DISCUSSION Genetic Transformation}

A total of 26 assays were carried out representing the management of 7,984 explants, submitted to Agrobacterium- mediated transformation process. Only 37 shoots were obtained from all of them (Table 1), which produces a mean transformation frequency of 1.12 of the total of shoot assays; each shoot-yielding assay, however, had its particular percentage. It is important to emphasize that the highest transformation frequency of independent experiments was obtained with two hours of bacteria incubation, more than 40 h of co-cultivation, and optical density from 0.8 to 1.1 , since it is quite probable that higher optical density coincides with the stationary phase of bacterial growth, leaving less activity to strains and thus lower transformation efficiency; likewise, it is probable that the strain working with low optical density $(>0.5)$ in the phase of growth lag and the time of co-cultivation, may be not sufficient for the bacterium to infect the tissues properly. Therefore, the obtained results partially agree with those reported by Mohri et al. (2003), who after 48 h of co-cultivation found better response in segments of leaves, stem, petiole, and root, but at incubation times not longer than $30 \mathrm{~min}$, and maximum optical density of 0.5 in petioles. Even though in the present research we worked with internodes determined by direct organogenesis response, it is considered that this way is the most appropriate for $P$. elongata, taking into account that the studies previous to trans- formation with species of genus Paulownia spp. had led to obtaining of calli and roots, not of shoots or complete plants, this factor being the most important of the expected results. Even when it had been necessary to utilize a great many initial explants, in the total of assays as well as in each of them particularly, in none of the cases fewer than 250 stem segments were used. At first we expected to obtain a larger number of shoots, starting from the selected organogetic route; however, this did not happen, partly due to the fact that although the kanamycin dose was not higher than $15 \mathrm{mg} \mathrm{L}^{-1}$ it is probable that it would have indirect effects on diminishing the capacity of forming shoots, even in the transformed tissues.

\section{Internode and Calli Transformation by Particle Acceleration}

Shoot formation were evaluated in each experiment with the possibility of having a transformants in a total of 20 assays, which represented the management of 6,474 explants submitted to the transformation process by particle acceleration through (PIG). Nineteen shoots were obtained (Table 1), generating a mean transformation percentage of 1.19 of the total of shoot assays; however, putting these results on a level with similar studies on $P$. elongata presents difficulties as a species, since so far, genetic transformation through particle acceleration has not been examined yet. Nevertheless, there is information of other forest species of the coniferous family, such as Pinus roxbughii, where direct biolistc transformed on mature embryos was made in order to incorporate bar gene, obtaining transformed plants from epicotyls and adventitious shoots. This approaches the system used in the present study, due to the fact that after biolistic 
Table 1. Response of assays with stem and callus samples of $P$. elongata, in X-GLUC substrate and by PCR analysis.

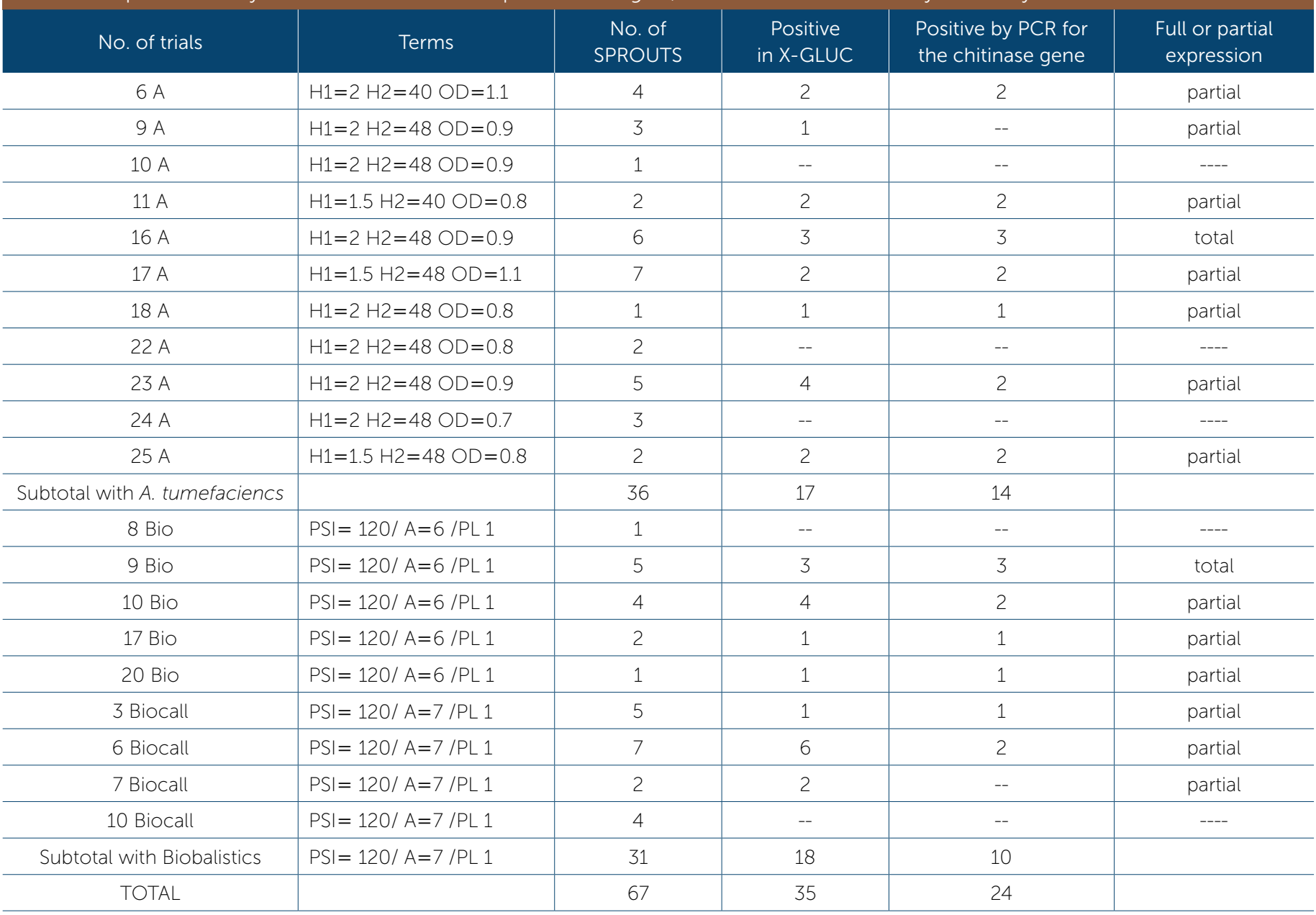

Footnote: A: Transformed by Agrobacterium

Bio: Transformed by bioballistics

Biocall: Callus transformed by bioballistics

$\mathrm{H1}$ : Hours of co-incubation with bacterium in liquid medium

H2: Hours of co-culture in solid medium

OD: Optical density of bacterial culture

PS1: Shot pressure

A7: Shot height

PL1: Plasmid with genes of interest contained plasmid

-- Without response

even when starting from sexual tissue in the beginning, finally the transformants are recovered from organogenesis; however, the usually preferred way for transformation by particle acceleration in conifers by $70 \%$ has been through somatic embryogenesis (Tang \& Newton 2003). The aforesaid is mainly due to an increment of bombed cells in calli of embryogenic type, which increases the possibility of transformation, once the somatic embryos derived from the transformed cells are being produced, since the organogenic way is associated to genetic changes by somaclonal variation. This would be in this particular caseof high risk, starting from the fact that the original material is a hybrid of high plasticity and yield, for which it is not desirable to alter these characteristics; since the objective and the point only was integrating the genes of interest without changing the original condition of $P$. elongate.
The calli were transferred at half strength recuperation media without antibiotics for seven days were sub cultivated in selection medium (MSSEL) during 30 days, and shoot production was evaluated in each experiment. The total number of conducted assays was 10 with an average of 24 calli for each; but with the highest transformation percentage to the order of 21.21, which is related to the fact that even though this has to do with a reduced number of 
calli each callus had $1.5 \mathrm{~cm}$ diameter on an average with greater impact surface for the tungsten particles, which in turn represented a larger number of possibly transformed cells, even when the way of indirect organogenesis was followed. It is important to emphasize that in the case of transformation by particle inflow gun system in forest species such as conifers,
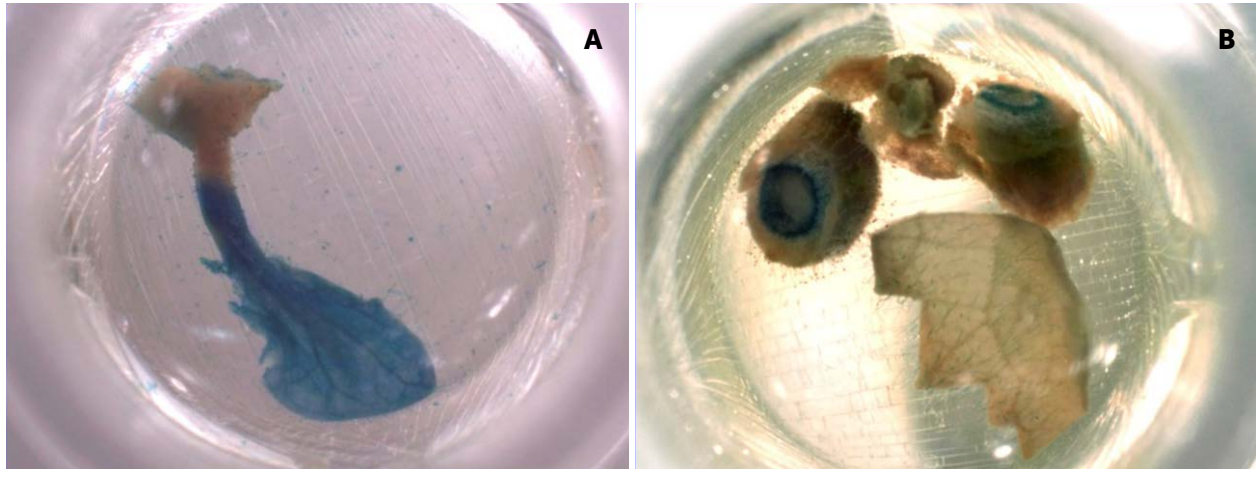

Figure 1: GUS expression in X-GLUC substrate of transformed tissues (A) total response, (B) Partial response somatic embryogenesis is of 70\% (Tang \& Newton 2003). The use of calli and genetic transformation in $P$. elongata with Agrobacteriummediated systems has been reported (Mohri et al., 2003) achieving transformed tissue and deriving in callus lines. On the other hand, Bergmann et al. (1999) report callus and root formation, after transforming with Agrobacterium rhizogenes; however, despite these advances, up to date, complete and stable transformation in $P$. elongata by bioballistic systems have not been reported, since there are only records of preliminary assays with temporary expression, like those carried out by Mohri and Shinohara (1996), who utilized a transformation system by particle inflow gun, in order to insert the luciferase gene in P. fortunei; however, they do not report stable expression neither complete plant development.

\section{Histochemical Evaluation and PCR Analysis of Shoots}

Tissue samples in X-GLUC substrate allowed evaluating GUS gene expression, blue coloration in tissues being observed with positive response to the expression of this gene. As a disadvantage that this may be a destructive test. At the end of the evaluation, it could be observed that only 35 out of the 67 shoots obtained and kept in selection medium resulted positive for GUS, 6 of these with total expression and 29 partially (Table 1, Figure 1); the fact of achieving shoots with partially transformed tissue indicates the majority presence of chimeras, whose transformed tissues can be identifiedeven though they are not fully transformed individuals - and starting from them, complete individuals can be generated. Mohri et al. (2003) report calli with total expression for the case of $P$. fortunei, whereas in the present study, all the calli obtained had partial expression. It must yet be clarified that $P$. fortunei was transformed with Agrobacterium (species) and in the present case $P$. elongata was transformed by particle inflow gun system. Most of the calli kept in selection medium resulted positive, at least partially. In this sense, mature Pinus roxbughii embryos, for example, were transformed by particle inflow gun system, generally obtaining partial transformants, from which complete individuals were identified and generated from such transformed tissues, inducing adventitious shoots (Parasharami et al., 2006). Therefore, shoots and calli from $P$. elongata were kept in selection medium, in order to subsequently identify the transformed tissues and generate complete individuals, which could be identified through histochemical X-GLUC analysis.

Molecular analysis by PCR allowed assessing the incorporation of the genes of interest in the transformants, presence of bands being observed in the shoots with positive response or band absence in nontransformed shoots. We emphasize the fact that 24 out of the 67 assessed elements showed positive response (Table 1, Figure 2), 35\% of the total. Interesting situations could be observed, like shoots having had partially positive response for GUS and negative response for PCR; or on the contrary, materials negative for GUS and positive for PCR. One of the main causes of chimeric effects is the fact that mostly partially transformed materials (chimeras) were obtained by Agrobacterium as well as by bioballistics, which brings about that tissue parts are taken for the tests, that may contain or not the transformed portions, which produces such responses in the moment of analysis.

\section{CONCLUSIONS}

It was possible to genetically transform $P$. elongata by the direct method of ballistics or indirectly by Agrobacterium tumefaciens-mediated transformation in order to incorporate genes of interest. Complete as well as partial transformants could be achieved in both 


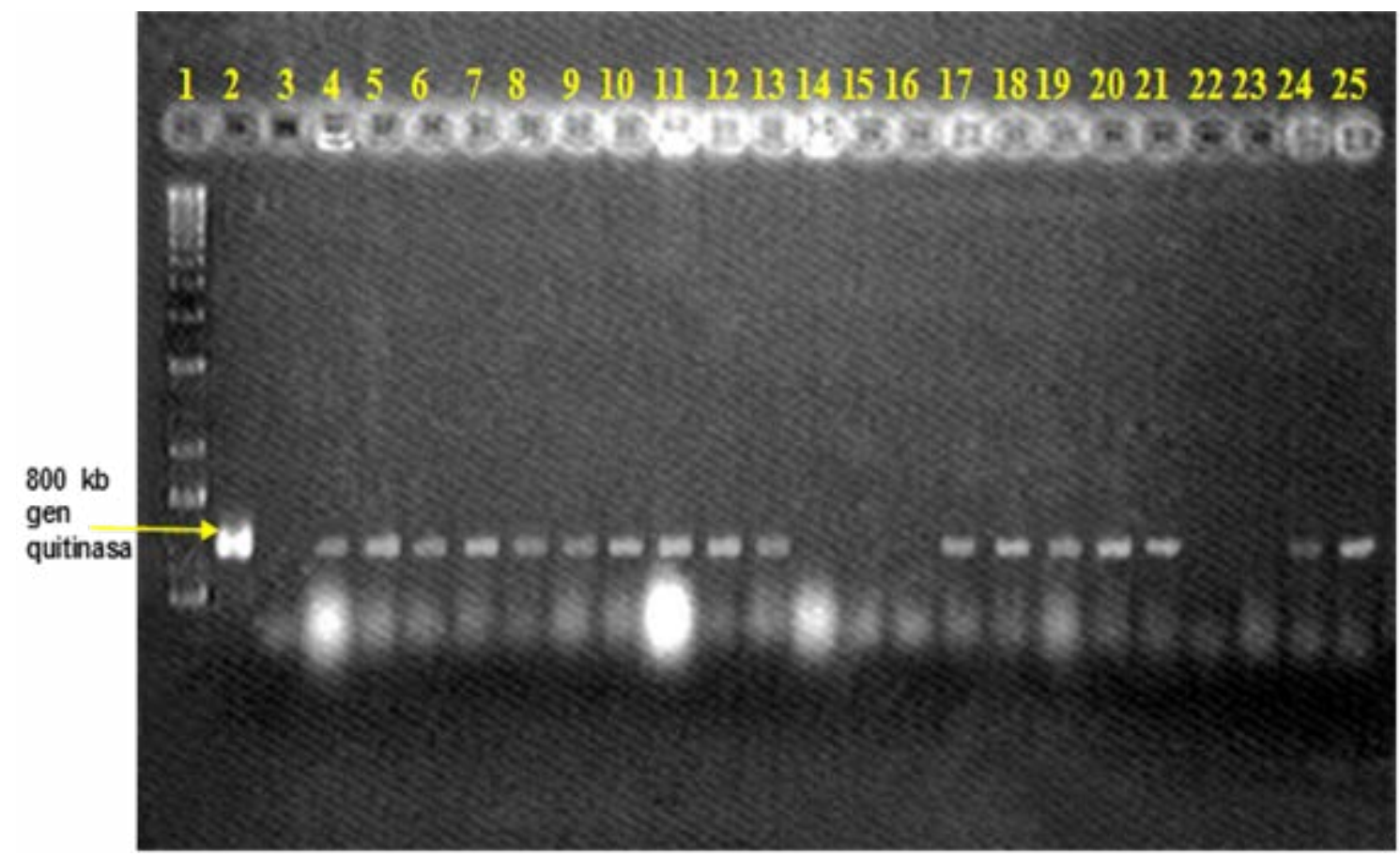

Figure 2: PCR test for chitinase gene integration to transformed $P$. elongata materials by direct and indirect transformation systems, in agar gel of 1.5\%, showing the results of Rail 1, stairs $1 \mathrm{~Kb}$, rail 2 positive control for chitinase gene, rail 3, negative control, rail 4-25 DNA tissue samples obtained in selection media.

systems, via direct organogenesis and indirectly for the case of transformed calli.

\section{REFERENCES}

Bergmann B.A. \& Moon H. K. 1997. In vitro adventitious shoot production in Paulownia. Plant Cell Reports 16: 315-318. doi $10.1007 / \mathrm{s} 002990050230$

Bergmann B.A., Lin. X. \& Whetten R. 1999. Susceptibility of Paulownia elongata to Agrobacterium and production of transgenic calli and hairy roots by in vitro inoculation. Plant Cell, Tissue and Organ Culture 55: 45-51. doi: 10.1023/A:1026481926560

Castillo-Martínez, C. R., Gutiérrez-Espinosa, M. A., Buenrostro-Nava, M. T., Cetina, A., \& Cadena-Iñiguez,.J. (2012). Regeneration of Paulownia elongata Steud. plants by direct organogenesis. Revista Mexicana de Ciencias Forestales, 3(10), 41-49.

Herrera-Estrella L., Depicker A., Van Montagu M., \& Schell J. 1983 Expression of chimaeric genes transferred into plant cells using a Ti-plasmid-derived vector. Nature, 303(5914): 209-213. doi:10.1038/303209a0

Horsch R.B., Fry J.N.L., Hoffman D., Eichholtz D., Rogers S.G. \& Fraley R.T. 1985. A simple and general method for transferring genes into plants. Science 227: 1229-1231. doi: 10.1126/ science.227.4691.1229

Ipecki, Z., \& Gozukirmizi N. (2003). Direct somatic, embryogenesis and synthetic seed production from Paulownia elongata. Plant Cell Reports. 22, 16-24. doi: 10.1007/s00299-003-0650-5

Ipecki, Z., \& Gozukirmizi N. (2004). Indirect somatic embryogenesis and plant regeneration from leaf and internodal explants of Paulownia elongata. Plant Cell Tissue and Organ Culture 79. 341-345. doi:10.1007/s11240-003-4632-7
Mehrotra, M. D. (1994). Basal and root rot of Paulownia fortunei caused by Rhizoctonia. Indian Forester 120 (6), 544-549.

Mehrotra, M. D. (1997). Diseases of Paulownia and their management. Indian Forester 123 (1), 66-72.

Mohri T. \& Shinohara K. 1996. A biolistic approach for the transfer and expression of a luciferase gene in Paulownia (Paulownia fortunei). Journal of Forest Research 1(1): 65-66.

Mohri T., Igasaki T. \& Shinohara, K. 2003. Agrobacterium-mediated transformation of paulownia (Paulownia fortunei). Plant Biotechnology 20(1): 87-91.

Parasharami, V.A., V.B. Naik, S. Von Arnold, R. Nadgauda S., \& Clapham, D.H. 2006. Stable trasformation of mature zygotic embryos and regeneration of transgenic plants of chir pine (Pinus roxbughii). Plant Cell Reports, 24: 708- 714. doi: 10.1007/s00299-0050019-Z

Song, S.L., T. Sato, K. Ishii, A. Saito \& Ohba, K. (1990). In vitro mass propagation by meristem culture of two mature trees of Paulownia catalpifolia. Journal of the Japanese Forestry Society, 72(6), 495-498. doi 10.11519/jjfs1953.72.6_495

Song, S. L., K. Suda, K. Ishii, A. Saito \& Ohba, K (1991). Plantlet regeneration from leaf and petiole explants of in vitro cultured Paulownia catalpifolia. Journal of the Japanese Forestry Society,73(1), 6063. DOI 10.11519/jjfs1953.73.1_60

Tang, R. C., Carpenter, S. B., Wittwer, R. F., \& Graves, D. H. (1980). Paulownia-a crop tree for wood products and reclamation of surface-mined land. Southern Journal of Applied Forestry, 4(1), 19-24.

Tang W. \& Newton R.J. 2005. Plant regeneration from callus cultures derived from mature zygotic embryos in white pine (Pinus strobus L.). Plant Cell Reports 24 (1): 1-9. doi 10.1007/s00299005-0914-3 
Tao D., W. Yao., Q Hu., S. Liu \& Huang, W. (2005). Transgenic Paulownia expressing shiva-1 gene has increased resistance to witches broom disease. Journal of Integrative Plant Biology 47(12),1500-1506. doi: 10.1111/j.1744-7909.2005.00168.x

Vain, P., N. Keen, J. Murillo, C. Rathus, C. Nemes \& Finer, J. (1993) Development of the particle inflow gun. Plant Cell, Tissue and Organ Culture, 33, 237-246. doi 10.1007/BF02319007

Zhu Z. H., C.J. Chao., X.Y. Lu \& Xiong Y G. 1986. Paulownia in China: cultivation and utilization. Asian Network of Biological Sciences. Singapore and International Developmental Research Centre. Canada pp.1-65

Zou, W., Q. Zhao, D. Cui \& Wang, B. (2006). Transformation of Populus deltoides with anti-PLD947 gene and chitinase gene. Scientia Silvae Sinicae, 42(1), 37-42

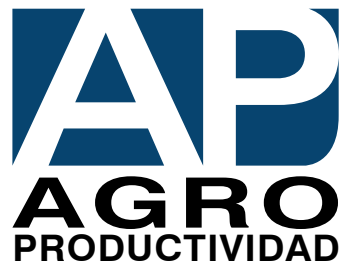

